\title{
Quantitative mid-infrared spectra of Allene and Propyne from room
}

\section{to high temperatures}

\author{
Et. Es-sebbar ${ }^{1}$, A. Jolly ${ }^{2}$, Y. Benilan ${ }^{2}$ and A. Farooq ${ }^{1 *}$ \\ ${ }^{1}$ Chemical Kinetics and Laser Sensors Laboratory, Clean Combustion Research Center, Division of \\ Physical Sciences and Engineering, King Abdullah University of Science and Technology (KAUST), \\ Thuwal 23955-6900, Saudi Arabia \\ ${ }^{2}$ Laboratoire Interuniversitaire des Systèmes Atmosphériques (LISA), UMR 7583 du CNRS, Universités \\ Paris-Est Créteil et Paris Diderot, Institut Pierre Simon Laplace, 61 Avenue du Général de Gaulle, 94010 \\ Créteil, France, France \\ *Corresponding author email : aamir.farooq@kaust.edu.sa, phone : +966-128082704
}




\begin{abstract}
Allene $\left(\mathrm{a}-\mathrm{C}_{3} \mathrm{H}_{4} ; \mathrm{CH}_{2} \mathrm{CCH}_{2}\right)$ and propyne $\left(\mathrm{p}-\mathrm{C}_{3} \mathrm{H}_{4} ; \mathrm{CH}_{3} \mathrm{C}_{2} \mathrm{H}\right)$ have attracted much interest because of their relevance to the photochemistry in astrophysical environments as well as in combustion processes. Both allene and propyne have strong absorption in the infrared region. In the present work, infrared spectra of $\mathrm{a}-\mathrm{C}_{3} \mathrm{H}_{4}$ and $\mathrm{p}-\mathrm{C}_{3} \mathrm{H}_{4}$ are measured in the gas phase at temperatures ranging from 296 to $510 \mathrm{~K}$. The spectra are measured over the $580-3400 \mathrm{~cm}^{-1}$ spectral region at resolutions of 0.08 and $0.25 \mathrm{~cm}^{-1}$ using Fourier Transform Infrared spectroscopy. Absolute integrated intensities of the main infrared bands are determined at room temperature and compared with values derived from literature for both molecules. Integrated band intensities are also determined as a function of temperature in various spectral regions.
\end{abstract}

Keywords: Allene; Propyne; infrared absorption cross-section; integrated intensities; FTIR 


\section{Introduction}

Allene $\left(\mathrm{a}-\mathrm{C}_{3} \mathrm{H}_{4} ; \mathrm{CH}_{2} \mathrm{CCH}\right)$ and propyne $\left(\mathrm{p}-\mathrm{C}_{3} \mathrm{H}_{4} ; \mathrm{CH}_{3} \mathrm{C}_{2} \mathrm{H}\right)$ have attracted much interest for a long time because of their relevance to the photochemistry in planetary environments [1-8]. More recently, infrared (IR) spectra at high temperatures have gained a lot of interest because of the warm atmospheres of exoplanets, known as "Hot Jupiters", which are now being extensively studied [9-10]. Furthermore, a- $\mathrm{C}_{3} \mathrm{H}_{4}$ and $\mathrm{p}-\mathrm{C}_{3} \mathrm{H}_{4}$ represent key intermediates in combustion processes [11-16]. They are ubiquitous and play a crucial role in the formation of propargyl radical, a key intermediate in the production of aromatic compounds and soot particles [11-13].

Both allene and propyne absorb strongly in the IR domain, (see Linnett et al. [17]; Rasmussen et al. [18]; Mills et al. [19]; Stone [20]; Koga et al. [21]; Kondo and Koga [22]; Maki and Pine [23]) thus providing possibilities for sensitive detection in extraterrestrial environments for both molecules. Allene may be present in Titan and in the atmosphere of giants planets including Jupiter [24] and Saturn [8,25]. However, only propyne has so far been detected in the atmosphere of Titan [1,3,26,27]. As pointed out by Teanby et al. [7], the determined abundance of propyne in Titan's atmosphere is questionable due to the uncertainties in the laboratory measurements. In addition, the absence of allene is difficult to explain by photochemical models since both isomers are expected to transform into each other, undergoing similar processes. It has been proposed that perhaps complete isomerization of $\mathrm{a}-\mathrm{C}_{3} \mathrm{H}_{4}$ into $\mathrm{p}-\mathrm{C}_{3} \mathrm{H}_{4}$ occurs.

In the mid-IR spectral domain, the strongest fundamental bands of allene are observed near 841

$\left(v_{10}\right), 999\left(v_{9}\right)$ and $1957 \mathrm{~cm}^{-1}\left(v_{6}\right)$. The strongest transitions of propyne in the mid-IR are observed near $633\left(v_{9}\right), 1452\left(v_{7}\right)$ and $3334 \mathrm{~cm}^{-1}\left(v_{1}\right)$. Over the last few decades, the 
spectroscopic characterization of a- $\mathrm{C}_{3} \mathrm{H}_{4}$ and $\mathrm{p}-\mathrm{C}_{3} \mathrm{H}_{4}$ in the laboratory has been the topic of many studies using various spectroscopic diagnostics. Fourier Transform Infrared (FTIR) spectroscopy studies have been used to analyze the IR spectra and determine vibrational assignments and molecular structure (see references [28-30]). High-resolution tunable diode laser spectroscopy has been used to determine line intensities and collisional broadening parameters [31-34] as well as rotational and molecular constants [35-38].

This paper is part of our studies on gas-phase spectroscopy of molecules relevant to the photochemistry in planetary atmospheres, warm exoplanetary atmospheres and combustion processes. To enable the study of allene and propyne in such environments, and in order to provide extensive information about the constituents of planetary atmospheres as well as their excitation processes, high quality IR spectra are needed. In combustion processes, IR data will be used for the development of high-temperature quantitative diagnostics to study the decomposition of allene and propyne using shock tube and rapid compression machines. In the present study, we report the IR spectra of $\mathrm{a}-\mathrm{C}_{3} \mathrm{H}_{4}$ and $\mathrm{p}-\mathrm{C}_{3} \mathrm{H}_{4}$ as a function of temperature (296 $-510 \mathrm{~K}$ ). Section 2 presents our experimental setup used to measure absorption spectra and in Section 3 we describe briefly the procedure used to retrieve cross-sections and integrated intensities. IR spectra and band assignments are presented in Section 4 and finally, we present the integrated intensities and the influence of high temperatures.

\section{Experimental Method}

IR spectra were measured between 580 and $3400 \mathrm{~cm}^{-1}$ using a Fourier Transform Infrared (FTIR) spectrometer (Bruker Vertex 80V). The experimental setup was described previously for the 
investigation of 1-butene and propylene (see Es-sebbar et al. [39-40]) and only a brief description is given here. A KBr beamsplitter, a Globar mid-IR source and a DLaTGS detector were used to record the spectra. Based on the maximum interferometer mirror displacement, spectral resolution up to $0.06 \mathrm{~cm}^{-1}$ can be reached. Here, entrance aperture diameters of 2 and 2.5 $\mathrm{mm}$ and a collimating mirror of $100 \mathrm{~mm}$ focal length were used. These settings results in spectral resolution of 0.08 and $0.25 \mathrm{~cm}^{-1}$. The interferograms were corrected with the Mertz phase function and the boxcar apodized interferograms were zero-filled to produce the final spectrum. The modulated IR light was transmitted through an optical cell, made of stainless steel and equipped with $\mathrm{KBr}$ windows. The cell placed inside the chamber of the FTIR instrument, has an optical path length of $10 \mathrm{~cm}$. To record spectra at high temperatures, the absorption cell was heated using a heating jacket connected to a controller system. The temperature was measured continuously with five type-K (Omega) thermocouples along the length of the absorption cell with an uncertainty less than $0.5 \%$.

Ultra-pure (99.999\%) a- $\mathrm{C}_{3} \mathrm{H}_{4}$ and $\mathrm{p}-\mathrm{C}_{3} \mathrm{H}_{4}$, purchased from Abdullah Hashim Industrial Gases \& Equipment Co. Ltd., were used for IR studies. Spectra were recorded with pure samples and also with a mixture of $4 \%$ a- $\mathrm{C}_{3} \mathrm{H}_{4}$ in $\mathrm{N}_{2}$. Measurements were made at various temperatures ranging from 296 to $510 \mathrm{~K}$. At each temperature, series of spectra were recorded between 580 and 3400 $\mathrm{cm}^{-1}$ for various pressures. The pressure was monitored using three Baratron capacitance gauges (20, 100, and 1000 Torr full-scale ranges). Before and after each measurement, 120 co-added scans were recorded with the cell evacuated to take into account any drift in the background intensity. The absorption cell was evacuated to about $1 \times 10^{-4}$ Torr using a turbo-molecular pump (Turbo-v 81-M Varian) backed by a rotary mechanical pump (Varian DS-102). For the roomtemperature $(296 \mathrm{~K})$ measurements, the entire FTIR compartment was evacuated to less than 0.1 
mbar to avoid absorption by $\mathrm{CO}_{2}$ and $\mathrm{H}_{2} \mathrm{O}$. For high-temperature measurements, $\mathrm{N}_{2}$ gas was used to purge the FTIR spectrometer. To calibrate the FTIR wavenumber scale and to assign the observed features with corresponding line positions, spectra of $\mathrm{CO}$ and $\mathrm{CH}_{4}$ gases were recorded and compared with the corresponding lines in the HITRAN database.

\section{Data Analysis}

The absorbance, $A_{v}$, can be written using the Beer-Lambert law:

$$
A_{v}=\ln \left(I_{0} / I\right)_{v}=\varepsilon_{v}(l p)
$$

where $I_{0}$ is the incident intensity recorded with the empty cell (background), $I$ is the transmitted intensity measured with $\mathrm{a}-\mathrm{C}_{3} \mathrm{H}_{4}$ or $\mathrm{p}-\mathrm{C}_{3} \mathrm{H}_{4}$ samples, $\varepsilon_{v}$ is the absorption coefficient at wavenumber $v$ in $\mathrm{cm}^{-1}$. atm ${ }^{-1}, l$ is the optical path length in $\mathrm{cm}$; and $p$ is the gas pressure in atm. The absorption coefficient $\varepsilon_{v}$ can be converted to cross-section values ( $\mathrm{cm}^{2} /$ molecule) using:

$$
\sigma_{v}=\left(\varepsilon_{v} / N\right)(T(K) / 273.15)
$$

where $N=2.68676 \times 10^{19} / \mathrm{cm}^{3}$ is the Loschmidt number at standard values of temperature and pressure (273.15 K/1013.25 mbar).

In order to determine the integrated band intensity $\left(S_{v}\right)$, given in $\mathrm{cm}^{-2}$. atm ${ }^{-1}$, the integrated absorbance $\left(\int A_{v} \mathrm{~d} v\right)$ is first calculated as a function of gas pressure for different a- $\mathrm{C}_{3} \mathrm{H}_{4}$ and $\mathrm{p}-$ $\mathrm{C}_{3} \mathrm{H}_{4}$ bands. Then integrated absorbance $\left(\int A_{v} \mathrm{~d} v\right)$ is plotted as a function of the product of the optical path length and the partial pressure of the sample $(l p)$ :

$$
\int A_{v} \mathrm{~d} v=(l p) \int \varepsilon_{v} \mathrm{~d} v=(l p) S_{v}
$$

The linear dependence of the integrated absorbance with $l p$ is systematically verified and the absolute integrated intensity $\left(S_{v}\right)$ is deduced from the slope of the linear fit. These integrated 
intensity values are compared with quantitative results taken from the PNNL database [41]. Absorbance spectra taken from PNNL database were first converted to cross-section values by combining Eqs (1-2) for an optical path length of $100 \mathrm{~cm}$ and a pressure of $1.013 \times 10^{-3}$ mbar. Cross-sections were integrated over the studied spectral regions to compare with our integrated band intensities.

Uncertainties in cross-section measurements result primarily from uncertainties in the measured absorbance, the optical path length, the gas pressure and the gas temperature. The uncertainty on the optical path length is less than $0.5 \%$ arising from the expansion of the cell as the temperature increases. The measured pressure has an uncertainty of less than $2 \%$, which results from the uncertainty in the Baratron measurement and the pressure variation due to the adsorption of the sample on the cell walls. The uncertainty in temperature is about $0.5 \%$, arising from the statistical error of the readings given by the five thermocouples and from the temperature gradient over the length of the optical cell. Due to relatively small absorption over $2800-3400$ $\mathrm{cm}^{-1}$ spectral region, the error on the absorbance can be higher. This weakness was compensated by performing measurements at higher pressures. The uncertainty due to the drift of the intensity signal was evaluated by measuring the background before and after sample measurements. The combination of all error sources yields an overall uncertainty of about $\pm 3 \%$ in the measured absorption cross-sections in the $580-2800 \mathrm{~cm}^{-1}$ range and $\pm 5 \%$ uncertainty in the relatively higher wave number range of $2800-3400 \mathrm{~cm}^{-1}$. 


\section{Results and Discussion}

\subsection{Allene Absorption Spectra}

\subsubsection{Room-Temperature Spectra and Vibrational Assignments}

Fig. 1 shows the IR cross-sections of allene at $296 \mathrm{~K}$ measured at spectral resolutions of 0.08 and $0.25 \mathrm{~cm}^{-1}$. For clarity, the recorded spectrum is divided into different regions. To avoid saturation of the absorption bands, spectra were recorded in a mixture of $4 \%$ a $-\mathrm{C}_{3} \mathrm{H}_{4} / \mathrm{N}_{2}$. Allene has eleven vibrational modes (see Table 1) but only seven modes are infrared active. Except for the low energy $v_{11}$ mode centered at $352 \mathrm{~cm}^{-1}$ which is not in the range of our instrument, all other active modes are observed in this study. Between 700 and $950 \mathrm{~cm}^{-1}$ (Fig. 1a) we observe the strongest absorption band due to the $v_{10}$ mode $\left(841 \mathrm{~cm}^{-1}\right)$. We also identify $v_{9}$ at $999 \mathrm{~cm}^{-1}$ (Fig. 1b) followed by $v_{7}$ at $1398 \mathrm{~cm}^{-1}$ and a strong overtone band at $1682 \mathrm{~cm}^{-1}\left(2 v_{10}\right)$ (Fig. 1c). In the spectral region between 1900 and $2000 \mathrm{~cm}^{-1}$ (Fig. 1d), the $v_{6}$ mode is observed $\left(1957 \mathrm{~cm}^{-1}\right)$ together with a small contribution of an overtone band which is $2 v_{9}$. The $\mathrm{CH}_{2}$ symmetric stretching mode $v_{5}\left(3015 \mathrm{~cm}^{-1}\right)$ (Fig. 1e) is also observed in our spectra together with the asymmetric $\mathrm{CH}_{2}$ stretching mode $v_{8}$ at $3086 \mathrm{~cm}^{-1}$ (Fig. 1f).

\subsubsection{Room-Temperature Integrated Band Intensities}

Absorption measurements are performed for various pressures to determine the integrated intensities for all bands of allene described above. Integrated absorbances (base-e) are plotted as a function of the product of the partial pressure of $\mathrm{a}-\mathrm{C}_{3} \mathrm{H}_{4}$ the and optical path length ( $p l$ ) (Fig. 2). Spectra are recorded in a mixture of $4 \%$ a- $-\mathrm{C}_{3} \mathrm{H}_{4} / \mathrm{N}_{2}$ for a maximum total pressure of 1 atm. As can be seen in Fig. 2, the resulting integrated absorbances show a clear linear dependence. For all selected spectral regions, high correlation coefficients of $\sim 0.99$ are obtained. The 
integrated intensities for various features are calculated from the slopes of the linear fits. Retrieved values and corresponding uncertainties are listed in Table 2. For comparison, values derived from the PNNL database [41] and Koga et al. [21] are also shown. Our results agree very well with the PNNL data, within the estimated uncertainties, except for the integrated intensity between 2950 and $3200 \mathrm{~cm}^{-1}$ where our result is higher by $19 \%$. Moreover, an excellent agreement is observed with the values from Koga et al. [21], except for the 1200 to $1500 \mathrm{~cm}^{-1}$ region where our measurements are higher by about $16 \%$.

\subsubsection{Variation of Absorption Spectra with Temperature}

The effect of the temperature on the IR spectra of allene is studied by recording spectra at 296, 405 and $510 \mathrm{~K}$. The variation of absorption cross-sections with temperature is studied using pure allene to achieve high signal-to-noise-ratio. We compared cross-section data obtained in pure sample with allene/ $\mathrm{N}_{2}$ mixture; reliable spectra were obtained and the instrument function did not affect pure sample measurements. Figure 3 shows the absorption cross-sections for all observed bands for all three temperatures. When temperature increases, we mainly observe a significant decrease of the sharp absorption peaks and an extension of the absorption to a wider range. A similar temperature dependence of IR cross-sections was previously observed and discussed for 1-butene [39] and propylene [40]. This effect is mainly due to changes in the vibrational and rotational population distribution.

Integrated band intensities at 405 and $510 \mathrm{~K}$ are determined similarly to the room-temperature band intensities. The retrieved intensities are shown in Fig. 4. Changing the temperature from 296 to $510 \mathrm{~K}$ leads to small variations in the integrated intensities with maximum differences 
reaching 13\%. These variations are higher than our expected measurement uncertainties, however, it is difficult to determine if the integrated intensity is temperature dependent or not since we did not observe a clear trend. The integrated intensity of each band system should generally be independent of temperature for isolated features comprising primarily fundamental vibrational bands [41-44]. However, as pointed out by earlier studies [45-47], anharmonicities, overlapping features from neighboring bands as well as contributions from overtones and combination/difference bands can be responsible for small variations of the integrated intensities with temperature.

\subsection{Propyne Absorption Spectra}

\subsubsection{Room-Temperature Spectra and Vibrational Assignments}

IR spectra of propyne at $296 \mathrm{~K}$ are shown in Figs. 5 (a-f) over the $580-3400 \mathrm{~cm}^{-1}$ region. All measurements are recorded using a $4 \% \mathrm{p}-\mathrm{C}_{3} \mathrm{H}_{4} / \mathrm{N}_{2}$ mixture. Spectra are recorded at a total pressure of 400 Torr to get data with high signal-to-noise ratio, except for the $580-700 \mathrm{~cm}^{-1}$ spectral region where spectra are recorded at 150 Torr to avoid signal saturation. The mid-IR spectra of propyne reveal several prominent features. The fundamental vibrational modes of propyne are listed in Table 3 along with the characteristic frequencies. In the low wavenumber range, $580-700 \mathrm{~cm}^{-1}$ (Fig. 5a), a very strong absorption band is observed near $633 \mathrm{~cm}^{-1}$ corresponding to the $v_{9} \mathrm{C}-\mathrm{H}$ bending mode. The region from 1200 to $1300 \mathrm{~cm}^{-1}$ is dominated by the $2 v_{9}$ overtone band (Fig. 5b) followed, between 1300 and $1600 \mathrm{~cm}^{-1}$ (Fig. 5c) by a feature belonging to the $\mathrm{CH}_{3}$ deformation mode $v_{7}$ peaking near $1452 \mathrm{~cm}^{-1}$. In the $2080-2200 \mathrm{~cm}^{-1}$ region (Fig. 5d), an absorption band is observed near $2142 \mathrm{~cm}^{-1}$ which is assigned to the $v_{3} \mathrm{C}-\mathrm{C}$ stretching mode. Two overlapping features appear in the $2800-3100 \mathrm{~cm}^{-1}$ domain 
corresponding to $v_{2}\left(2918 \mathrm{~cm}^{-1}\right)$ and $v_{6}\left(3008 \mathrm{~cm}^{-1}\right)$ (Fig. 5e). In the $3275-3400 \mathrm{~cm}^{-1}$ range (Fig. 5f), the $v_{1}\left(3334 \mathrm{~cm}^{-1}\right) \mathrm{CH}$ stretching mode can be observed. All vibrational modes of propyne are active but the modes $v_{4}, v_{5}, v_{8}$ are too weak to be measured in this work (see Kondo and Koga [22] for estimated intensities). Propyne also possesses a strong mode at $327 \mathrm{~cm}^{-1}$ which is out of the range of our experimental setup.

\subsubsection{Room-Temperature Integrated Band Intensities}

As in the case of allene, the band intensities of propyne are determined from the linear fit of the integrated absorbance versus the product $(p l)$. The spectra of $\mathrm{p}-\mathrm{C}_{3} \mathrm{H}_{4}$ have been divided into six spectral regions for the determination of integrated intensities. Fig. 6 shows the integrated absorbance versus $p l$ for the considered six spectral regions. Spectra are recorded in a mixture of $4 \% \mathrm{p}-\mathrm{C}_{3} \mathrm{H}_{4} / \mathrm{N}_{2}$ for a total pressure up to 150 Torr in the case of $580-700 \mathrm{~cm}^{-1}$ region to avoid any saturation and up to $1 \mathrm{~atm}$ for all other spectral regions. A linear dependence has been observed with a high correlation factor for all regions. Since the $2800-3100 \mathrm{~cm}^{-1}$ region contains two strongly overlapping bands $\left(v_{2}\right.$ and $\left.v_{6}\right)$, a single integration has been carried out to cover the two features. By using Eq. (3), integrated intensities are derived and the resulting values and corresponding uncertainties are listed in Table 4. The estimated experimental uncertainties are better than 5\%. For comparison, Table 4 also includes the derived integrated intensities from the PNNL database [41] and the measured band intensities by Kondo and Koga [22]. The overall agreement is very good since the largest difference is only $7.3 \%$ for the weak $v_{3}$ band.

\subsubsection{Variation of Absorption Spectra with Temperature}


Fig. 7 shows the IR spectra of propyne measured at 296, 361, 405 and $493 \mathrm{~K}$ for all six spectral regions. As expected, the temperature affects the shape of all the absorption bands. With increasing temperature, the intensities of the $Q$ branches decrease while the $P$ and $R$ branches get wider and have their maxima moving away from the band centre.

Integrated intensities for propyne are also determined for all four temperatures and all six absorption regions. The results are shown in Fig. 8. The integrated band intensities do not seem to be constant over the investigated temperature range as the observed variations are larger than our expected uncertainties. The largest difference is observed mainly for the $v_{1}$ band where the integrated intensity decreases by about $18 \%$ when the temperature increases from 296 to $493 \mathrm{~K}$ (see Fig. 8). As observed for allene, such variations may point towards real variation of the integrated intensity with temperature due to the presence of overtone and combination bands. However, we do not observe a clear trend for the change of integrated intensities with temperature which makes it difficult to make a conclusive argument if the integrated intensities indeed exhibit some temperature dependence or not. There is little work in the literature that addresses temperature dependence of integrated intensities and further investigations are needed to ascertain this seemingly anomalous behavior.

\section{Conclusion}

The integrated intensities of allene and propyne measured in this work at room temperature are in very good agreement with previously published results. For both molecules, we observe variations of the integrated intensities with temperature with maximum variation being about $20 \%$. Such variations are probably real since they are larger than our expected uncertainties and 
comparable with results from similar studies on other molecules. Measured spectra of allene and propyne are provided as Supplementary Material. 


\section{Acknowledgements}

Research reported in this publication was supported by the King Abdullah University of Science and Technology (KAUST). The SIPAT program is funded in part by the Programme National de Planétologie of the Institut National des Sciences de l'Univers. 


\section{References}

[1] A. Coustenis, B. Bézard, D, Gautier, Icarus 80 (1989) 54-76.

[2] B. Bézard, A. Coustenis, C. P. McKay, Icarus 113 (1995) 267-276.

[3] T. de Graauw, H. Feuchtgruber, B. Bézard, P. Drossart, T. Encrenaz, D.A. Beintema, J. Griffin, A. Heras, M.F. Kessler, K. Leech, E. Lellouch, A. Morris, P.R. Roelfsema, M. RoosSerote, A. Salama, B. Vandenbussche, E.A. Valentijn, G.R. Davis, D.A. Naylor, Astron. Astrophys. 321 (1997) L13-L16.

[4] B. Bézard, P. Drossart, T. Encrenaz, H. Feuchtbruber, Icarus 155 (2001) 492-500.

[5] A. Coustenis, A. Salama, B. Schulz, S. Ott, E. Lellouch, Th. Encrenaz, D. Gautier, H. Feuchtgruber, Icarus 161 (2003) 383-403.

[6] S. Vinatier, B. Bézard, Th. Fouchet, N. A. Teanby, R. de Kok, P. G.J. Irwin, B. J. Conrath, C.

A. Nixon, P. N. Romani, F. M. Flasar, A. Coustenis, Icarus 188 (2007) 120-138.

[7] N.A. Teanby, P.G.J. Irwin, R. de Kok, A. Jolly, B. Bézard, C.A. Nixon, S.B. Calcutt, Icarus 202 (2009) 620-631.

[8] S. Guerlet, Th. Fouchet, B. Bézard, J. I. Moses, L. N. Fletcher, A. A. Simon-Miller, F. M. Flasar, Icarus 209 (2010) 682-695.

[9] J. Tennyson, S. N. Yurchenko, Monthly Notices of the Royal Astronomical Society 425 (2012) 21-33.

[10] J. Tennyson, C. Hill, S. N. Yurchenko, AIP Conference Proceedings, 1545 (2013) 186.

[11] M. Frenklach, S. Taki, M. B. Durgaprasad, R. A. Matula, Combustion and Flame 54 (1983) 81-101.

[12] M. Frenklach, T. Yuan, M. K. Ramachandra, Energy Fuels 2 (1988) 462-480.

[13] M. J. Castaldi, A. M. Vincitore, S. M. Senkan, Combust. Sci. Technol. 107 (1995) 1-19.

[14] H. Curran, J. M. Simmie, Symposium (International) on Combustion 26 (1996) 613-620.

[15] R. Fournet, J. C. Bauge, F. Battin-Leclerc, Inter. Journal of Chem. Kinetics, 31 (1999) 361379.

[16] T. Faravelli, A. Goldaniga, L. Zappella, E. Ranzi, P. Dagaut and M. Cathonnet, Proceedings of the Combustion Institute 28 (2000) 2601-2608.

[17] J. W. Linnett, W. H. Avery, J. Chem. Phys. 6 (1938) 686-691.

[18] R. S. Rasmussen, R. R. Brattain, J. Chem. Phys. 15 (1947) 120-130.

[19] I. M. Mills, W. L. Smith, J. L. Duncan, J. Mol. Spectrosc. 16 (1965) 349-377. 
[20] J. M. R. Stone, J. Mol. Spectrosc. 38 (1971) 503-507.

[21] Y. Koga, S. Kondo, T. Nakanaga, S. Saëki, J. Chem. Phys. 71 (1979) 2404-2411.

[22] S. Kondo, Y. Koga, J. Chem. Phys. 69 (1978) 4022-4031.

[23] A. G. Maki, A. S. Pine, J. Mol. Spectrosc. 112 (1985) 459-481.

[24] G.R. Gladstone, M. Allen, Y.L. Yung, Icarus, 119 (1996) 1-52.

[25] R. Prangé, T. Fouchet, R. Courtin, J.E.P. Connerney, J. C. McConnell, Icarus 180 (2006) 379-392.

[26] W.C. Maguire, R.A. Hanel, D.E. Jennings, V.G. Kunde, R.E. Samuelson, Nature 292 (1981) 683-686.

[27] A. Coustenis, R.K. Achterberg, B.J. Conrath, D.E. Jennings, A. Marten, D. Gautier, C.A. Nixon, F.M. Flasar, N.A. Teanby, B. Bézard, R.E. Samuelson, R.C. Carlson, E. Lellouch, G.L. Bjoraker, P.N. Romani, F.W. Taylor, Patrick G.J. Irwin, Thierry Fouchet, A. Hubert, G.S. Orton, V.G. Kunde, S. Vinatier, J. Mondellini, M.M. Abbas, R. Courtin, Icarus 189 (2007) 35-62.

[28] W. F. Wang, J. M. Sirota, D.C. Reuter, J. Mol. Spectrosc. 194 (1999) 256-268.

[29] W. F. Wang, J. M. Sirota, D. C. Reuter, J. Mol. Spectrosc. 198 (1999) 201-208

[30] F. Hegelund, N. Andresen, J. Mol. Spectrosc. 149 (1991) 305-313.

[31] G. Blanquet, J. Walrand, Spectrochimica Acta Part A: Mol. Spectrosc. 48 (1992) 12311233.

[32] J. M. Sirota, D. C. Reuter, J. Frye, J. Quant. Spectrosc. Radiat. Transfer, 58 (1997)145-149.

[33] L. Fissiaux, G. Blanquet, M. Lepère, J. Quant. Spectrosc. Radiat. Transfer, 127 (2013) 7881.

[34] L. Fissiaux, G. Blanquet, J. C. Populaire, M. Lepère, J. Mol. Spectrosc. 296 (2014) 24-27.

[35] R. C. Lord, P. Venkateswarlu, J. Chem. Phys. 20 (1952) 1237-1247.

[36] P. P. Arcas, C. Haeusler, C. MeyerC, N. Van-Thanh, P. Barchewitz, Journal de physique 25 (1964) 667-672.

[37] J. Pliva, C. A. Martin, J. Mol. Spectrosc. 91 (1982) 218-237.

[38] Y. Ohshima, S. Yamamoto, K. Kuchitsu, J. Mol. Spectrosc. 117 (1986) 138-151.

[39] Et. Es-sebbar, Y. Bénilan Y, A. Farooq, J. Quant. Spectrosc. Radiat. Transfer 115 (2013) 112. 
[40] Et. Es-sebbar, M. Alrefae, A. Farooq, J. Quant. Spectrosc. Radiat. Transfer 133 (2014) 559569.

[41] S. Sharpe, T. Johnson, R. Sams, P. Chu, G. Rhoderick, P. Johnson, Appl. Spectrosc. 58 (2004) 1452-1461.

[42] C. Chackerian, S. W Sharpe, T A. Blake, J. Quant. Spectrosc. Radiat. Transfer 82 (2003) $429-441$.

[43] J. C. Breeze, C. C. Ferriso, C. B. Ludwig, W. Malkmus, The Journal of Chemical Physics 42 (1965) 402-406.

[44] J. J. Harrison, N. D. C. Allen, P. F. Bernath, J. Quant. Spectrosc. Radiat. Transfer 111 (2010) 357-363.

[45] R. L. Sams, S. W. Sharpe, T. J. Johnson, Presentation in the $60^{\text {th }}$ international symposium on molecular spectroscopy at Columbus., Ohio, US, 2005.

[46] S. J. Yao, J. Overend, Spectrochim Acta 32 (1976) 1059-1065.

[47] W. F. Wang, A. Stevenson, D. C Reuter, J. M. Sirota, Spectrochim Acta Part A. 57 (2001) $1603-1610$. 
Table 1. Vibrational modes of allene. The peak positions correspond to the maximum value of the cross-sections. (w: weak, m: medium, s: strong, vs: very strong)

\begin{tabular}{|c|c|c|}
\hline Band & Peak position, $\mathrm{cm}^{-1}$ & Vibrational assignment \\
\hline$v_{1}\left(a_{1}\right)$ & 3015 (not observed) & $\mathrm{CH}_{2}$ stretching \\
\hline$v_{2}\left(a_{1}\right)$ & 1443 (not observed) & $\mathrm{CH}_{2} \mathrm{scis}$ \\
\hline$v_{3}\left(a_{1}\right)$ & 1073 (not observed) & CC stretching \\
\hline$v_{4}\left(b_{1}\right)$ & 865 (not observed) & $\mathrm{CH}_{2}$ twist \\
\hline$v_{5}\left(b_{2}\right)$ & $3015(w)$ & $\mathrm{CH}_{2}$ stretching \\
\hline$v_{6}\left(b_{2}\right)$ & $1957(\mathrm{~m})$ & CC stretching \\
\hline$v_{7}\left(b_{2}\right)$ & $1398(\mathrm{~m})$ & $\mathrm{CH}_{2}$ scis \\
\hline$v_{8}(e)$ & $3086(\mathrm{~m})$ & $\mathrm{CH}_{2}$ stretching \\
\hline$v_{9}(e)$ & 999 (s) & $\mathrm{CH}_{2}$ rock \\
\hline$v_{10}(e)$ & $841(v s)$ & $\mathrm{CH}_{2}$ wag \\
\hline$v_{11}(e)$ & 352 (out of range) & CCC bend \\
\hline
\end{tabular}


Table 2. Integrated band intensities at $296 \mathrm{~K}$, obtained using a $4 \%$ allene/ $\mathrm{N}_{2}$ mixture and spectral resolutions of 0.08 and $0.25 \mathrm{~cm}^{-1}$ compared to PNNL data of Sharpe et al. [41] (resolution: 0.112 $\mathrm{cm}^{-1}$ ) and Koga et al. [21] (resolution: $1 \mathrm{~cm}^{-1}$ ). The percentage difference between the present data and the literature is given by: $\% \delta=100 \times\left(S_{\text {this work }}-S_{\text {literature }}\right) / S_{\text {literature }}$

\begin{tabular}{|c|c|c|c|c|c|c|c|}
\hline $\begin{array}{l}\text { Vibrational } \\
\text { modes }\end{array}$ & $\begin{array}{l}\text { Wavenumber } \\
\text { range }\left(\mathrm{cm}^{-1}\right)\end{array}$ & $\begin{array}{c}S_{\text {band }}\left(296 \mathrm{~K}^{-1}\right) \\
\mathrm{cm}^{-2} \mathrm{~atm}^{-1} \\
\text { This work }\end{array}$ & $\begin{array}{c}S_{\text {band }} \times 10^{-18} \\
\text { cm/molecule } \\
\text { This work }\end{array}$ & $\begin{array}{c}S_{\text {band }} \times 10^{-18} \\
\text { cm/molecule } \\
\text { Sharpe et al. [41] }\end{array}$ & $\begin{array}{c}S_{\text {band }} \times 10^{-18} \\
\mathrm{~cm} / \text { molecule } \\
\text { Koga et al. [21] }\end{array}$ & $\begin{array}{l}\% \delta \\
\text { with [41] }\end{array}$ & $\begin{array}{c}\% \delta \delta \\
\text { with [21] }\end{array}$ \\
\hline$v_{5}+v_{8}$ & $2950-3200$ & $49.56 \pm 2.5$ & $2.00 \pm 0.1$ & $1.68 \pm 0.03$ & 2.06 & +19.0 & -2.9 \\
\hline$v_{6}+2 v_{9}$ & $1900-2000$ & $212.8 \pm 6.0$ & $8.58 \pm 0.24$ & $8.22 \pm 0.22$ & 8.11 & +4.4 & +5.8 \\
\hline $2 v_{10}$ & $1600-1800$ & $33.4 \pm 1.2$ & $1.35 \pm 0.05$ & $1.37 \pm 0.05$ & --- & -1.5 & --- \\
\hline $\boldsymbol{v}_{7}$ & $1200-1500$ & $33.6 \pm 1.5$ & $1.35 \pm 0.06$ & $1.41 \pm 0.03$ & 1.16 & -4.2 & +16.4 \\
\hline$v_{9}$ & $950-1150$ & $36.2 \pm 1.3$ & $1.46 \pm 0.05$ & $1.42 \pm 0.12$ & 1.46 & +2.8 & 0 \\
\hline$v_{10}$ & $700-950$ & $375.9 \pm 6.6$ & $15.2 \pm 0.3$ & $15.51 \pm 1.71$ & 15.1 & -2.0 & +0.7 \\
\hline
\end{tabular}


Table 3. Vibrational modes of propyne. The peak positions correspond to the maximum value of the cross-sections. (w: weak, m: medium, s: strong, vs: very strong)

\begin{tabular}{ccc}
\hline Band & Peak position, cm $^{-1}$ & Vibrational assignment \\
\hline$v_{1}\left(\mathrm{a}_{1}\right)$ & $3334(\mathrm{vs})$ & $\mathrm{CH}$ stretching \\
$v_{2}\left(\mathrm{a}_{1}\right)$ & $2918(\mathrm{~s})$ & $\mathrm{CH}$ stretching \\
$v_{3}\left(\mathrm{a}_{1}\right)$ & $2142(\mathrm{~m})$ & $\mathrm{CC}$ stretching \\
$v_{4}\left(\mathrm{a}_{1}\right)$ & $1382($ not observed) & $\mathrm{CH}_{3}$ deformation \\
$v_{5}\left(\mathrm{a}_{1}\right)$ & $931($ not observed) & $\mathrm{CC}$ stretching \\
$v_{6}(\mathrm{e})$ & $3008(\mathrm{~s})$ & $\mathrm{CH}_{3}$ stretching \\
$v_{7}(\mathrm{e})$ & $1452(\mathrm{~s})$ & $\mathrm{CH}_{3}$ deformation \\
$v_{8}(\mathrm{e})$ & $1053($ not observed) & $\mathrm{CH}$ rock \\
$v_{9}(\mathrm{e})$ & $633(\mathrm{vs})$ & $\mathrm{CH}$ bend \\
$v_{10}(\mathrm{e})$ & $327($ out of range) & $\mathrm{CCC}$ bend \\
\hline
\end{tabular}


Table 4. Integrated band intensities at $296 \mathrm{~K}$, obtained using a $4 \%$ propyne $/ \mathrm{N}_{2}$ mixture and spectral resolution of 0.08 and $0.25 \mathrm{~cm}^{-1}$ compared to PNNL of Sharpe et al. [41] (resolution: $0.112 \mathrm{~cm}^{-1}$ ) and Kondo and Koga [22] (resolution: $0.1 \mathrm{~cm}^{-1}$ ). Here, $\% \delta=100 \times$ $\left(S_{\text {thiswork }}-S_{\text {literature }}\right) / S_{\text {literature }}$

\begin{tabular}{|c|c|c|c|c|c|c|c|}
\hline $\begin{array}{l}\text { Vibrational } \\
\text { modes }\end{array}$ & $\begin{array}{c}\text { Wavenumber } \\
\text { range }\left(\mathrm{cm}^{-1}\right)\end{array}$ & $\begin{array}{l}S_{\text {band }} \\
\text { cm }^{-2} \cdot \text { atm }^{-1} \\
\text { This work }\end{array}$ & $\begin{array}{c}S_{\text {band }} \times 10^{-18} \\
\text { cm/molecule } \\
\text { This work }\end{array}$ & $\begin{array}{c}S_{\text {band }} \times 10^{-18} \\
\text { cm/molecule } \\
\text { Sharpe et al. } \\
\text { [41] }\end{array}$ & $\begin{array}{c}S_{\text {band }} \times 10^{-18} \\
\mathrm{~cm} / \mathrm{molecule} \\
\text { Kondo et Koga } \\
{[22]}\end{array}$ & $\begin{array}{l}\% \delta \\
\text { with } \\
{[41]}\end{array}$ & $\begin{array}{l}\% \delta \\
\text { with } \\
{[22]}\end{array}$ \\
\hline$v_{1}$ & $3275-3400$ & $186.58 \pm 7.55$ & $7.53 \pm 0.30$ & $7.45 \pm 0.65$ & $7.5 \pm 0.5$ & +1.1 & +0.4 \\
\hline$v_{2}+v_{6}$ & $2800-3100$ & $131.25 \pm 6.52$ & $5.30 \pm 0.26$ & $5.12 \pm 0.32$ & $5.4 \pm 0.6$ & +3.5 & -1.8 \\
\hline $\boldsymbol{V}_{3}$ & $2080-2200$ & $21.87 \pm 0.63$ & $0.88 \pm 0.02$ & $0.82 \pm 0.04$ & $0.88 \pm 0.05$ & +7.3 & $\mathbf{0}$ \\
\hline$v_{7}$ & $1300-1600$ & $73.68 \pm 1.20$ & $2.97 \pm 0.05$ & $2.98 \pm 0.27$ & $2.97 \pm 0.3$ & -0.3 & $\mathbf{0}$ \\
\hline $2 v_{9}$ & $1200-1300$ & $69.20 \pm 1.20$ & $2.79 \pm 0.05$ & $2.79 \pm 0.26$ & - & 0 & --- \\
\hline$v_{9}$ & $580-700$ & $371.12 \pm 8.0$ & $14.96 \pm 0.32$ & $14.75 \pm 1.52$ & $14.50 \pm 0.8$ & +1.4 & +3.2 \\
\hline
\end{tabular}


Fig. 1. Allene absorption cross-sections between 700 and $3200 \mathrm{~cm}^{-1}$ at $296 \mathrm{~K}$. Spectra are recorded for $4 \%$ a- $\mathrm{C}_{3} \mathrm{H}_{4} / \mathrm{N}_{2}$ mixture and the total pressure is 100 Torr. The main features are identified and summarized in Table 1. Spectra between 700 and 1150 are recorded at spectral resolution of $0.08 \mathrm{~cm}^{-1}$. Spectra in the $1200-3200 \mathrm{~cm}^{-1}$ range are recorded at $0.25 \mathrm{~cm}^{-1}$ resolution
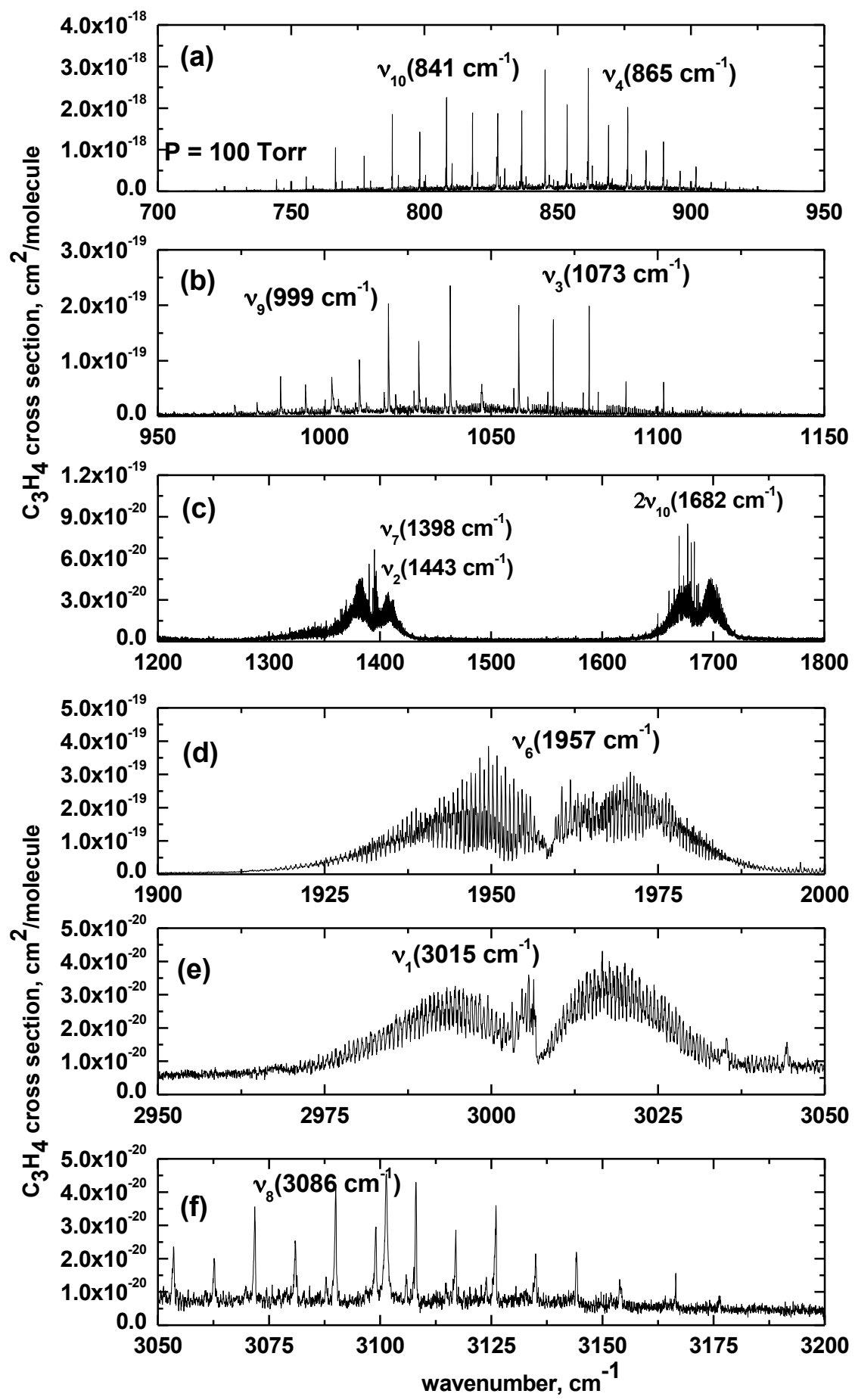
Fig. 2. Integrated absorbance (base-e) of allene $\left(a-\mathrm{C}_{3} \mathrm{H}_{4}\right)$ as a function of the product of its partial pressure and optical path length for various wavenumber regions. Spectra are recorded in a mixture of $4 \%$ a- $\mathrm{C}_{3} \mathrm{H}_{4} / \mathrm{N}_{2}$ for a total pressure up to $1 \mathrm{~atm}$.

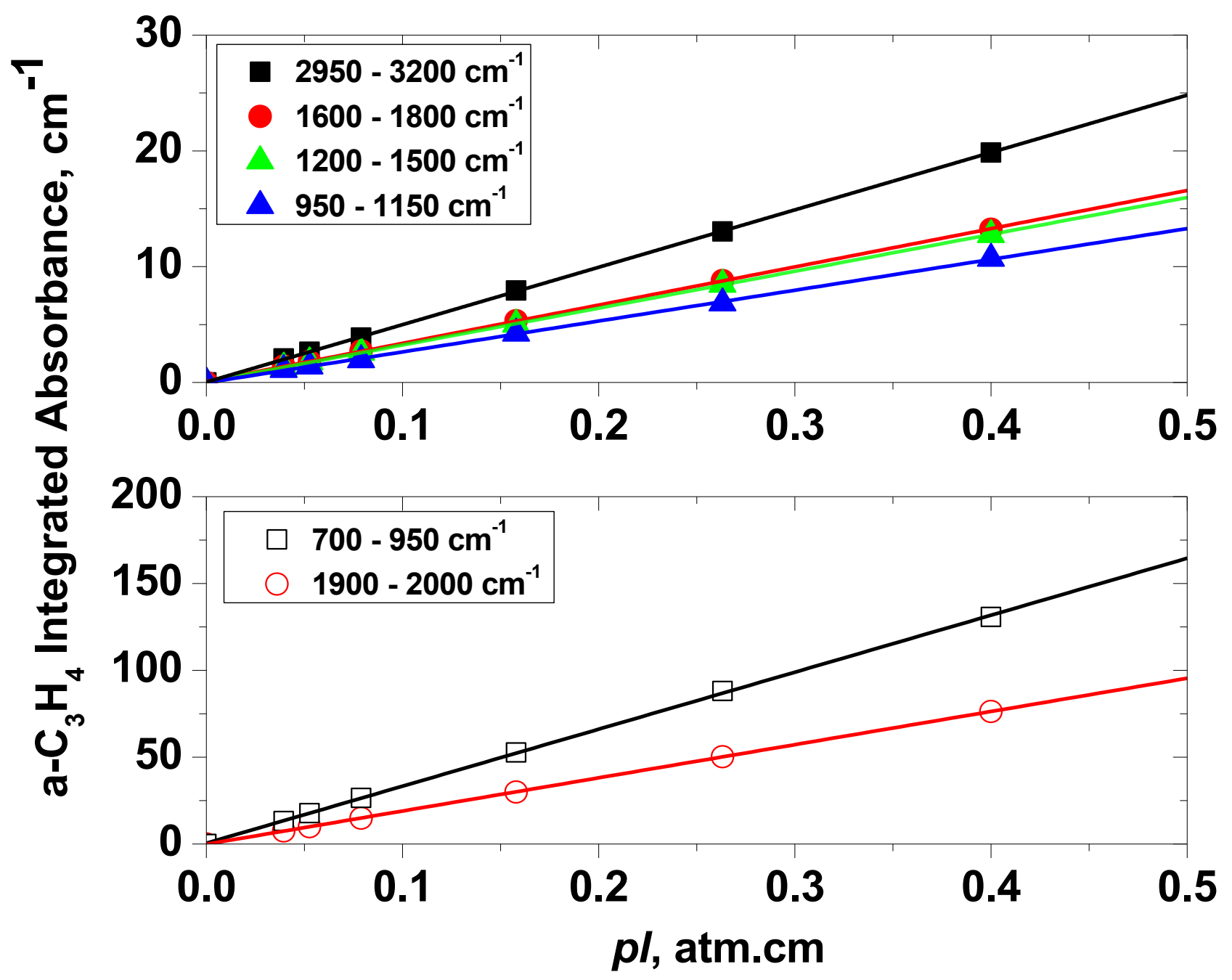


Fig. 3. IR cross-section for $\mathrm{a}-\mathrm{C}_{3} \mathrm{H}_{4}$ at 296,405 and $510 \mathrm{~K}$. Spectra are recorded with a pure sample at low pressures: (5 Torr for $700-950 \mathrm{~cm}^{-1}$ range; 50 Torr for $1350-1725 \mathrm{~cm}^{-1}$ and 20 Torr for all other spectral domains). The resolution is $0.08 \mathrm{~cm}^{-1}$ in the $700-1150 \mathrm{~cm}^{-1}$ range and $0.25 \mathrm{~cm}^{-1}$ between 1200 and $3150 \mathrm{~cm}^{-1}$
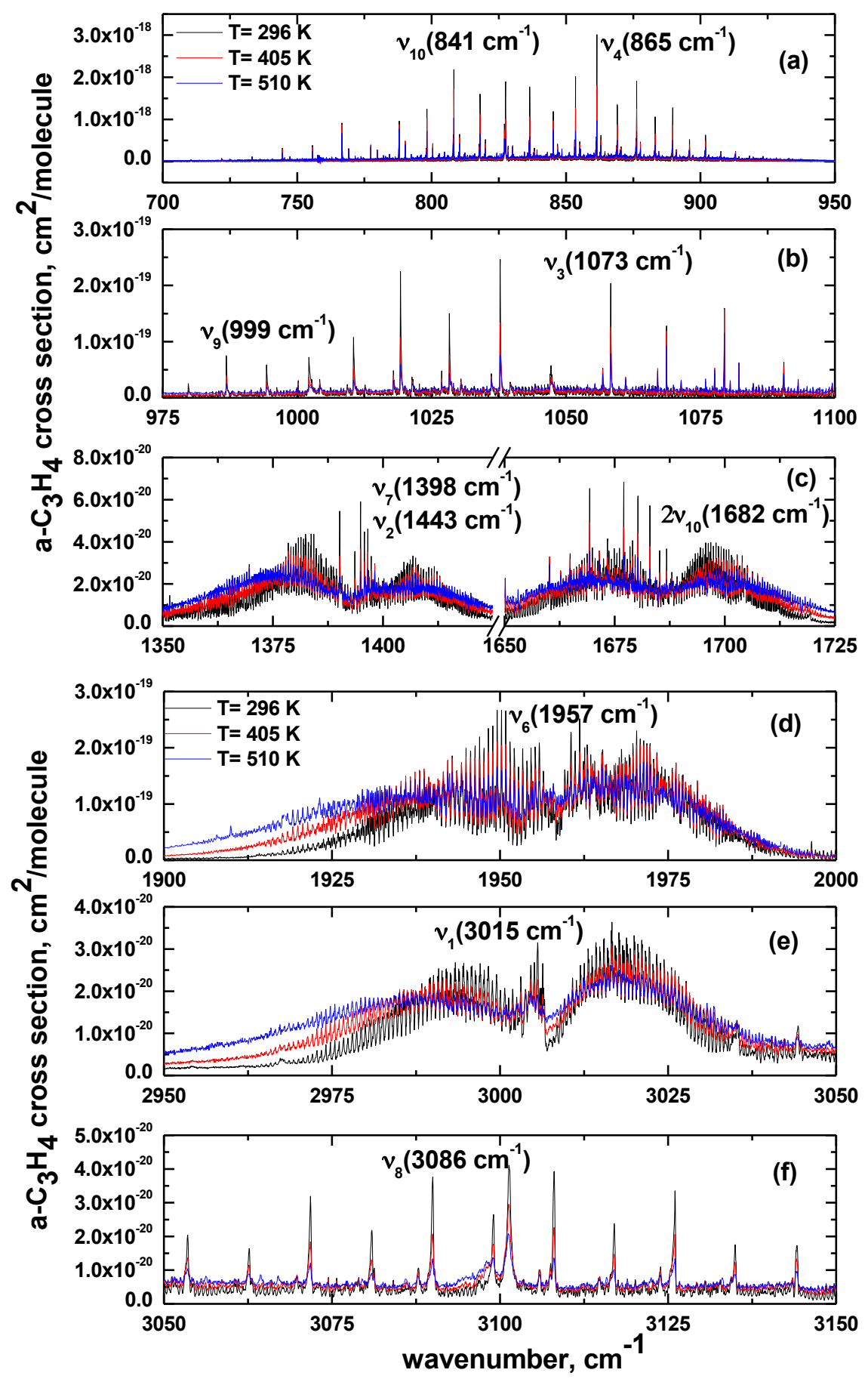
Fig. 4. Integrated band intensities as a function of temperature for various bands of a- $\mathrm{C}_{3} \mathrm{H}_{4}$. Temperature is changed from 296 to $510 \mathrm{~K}$

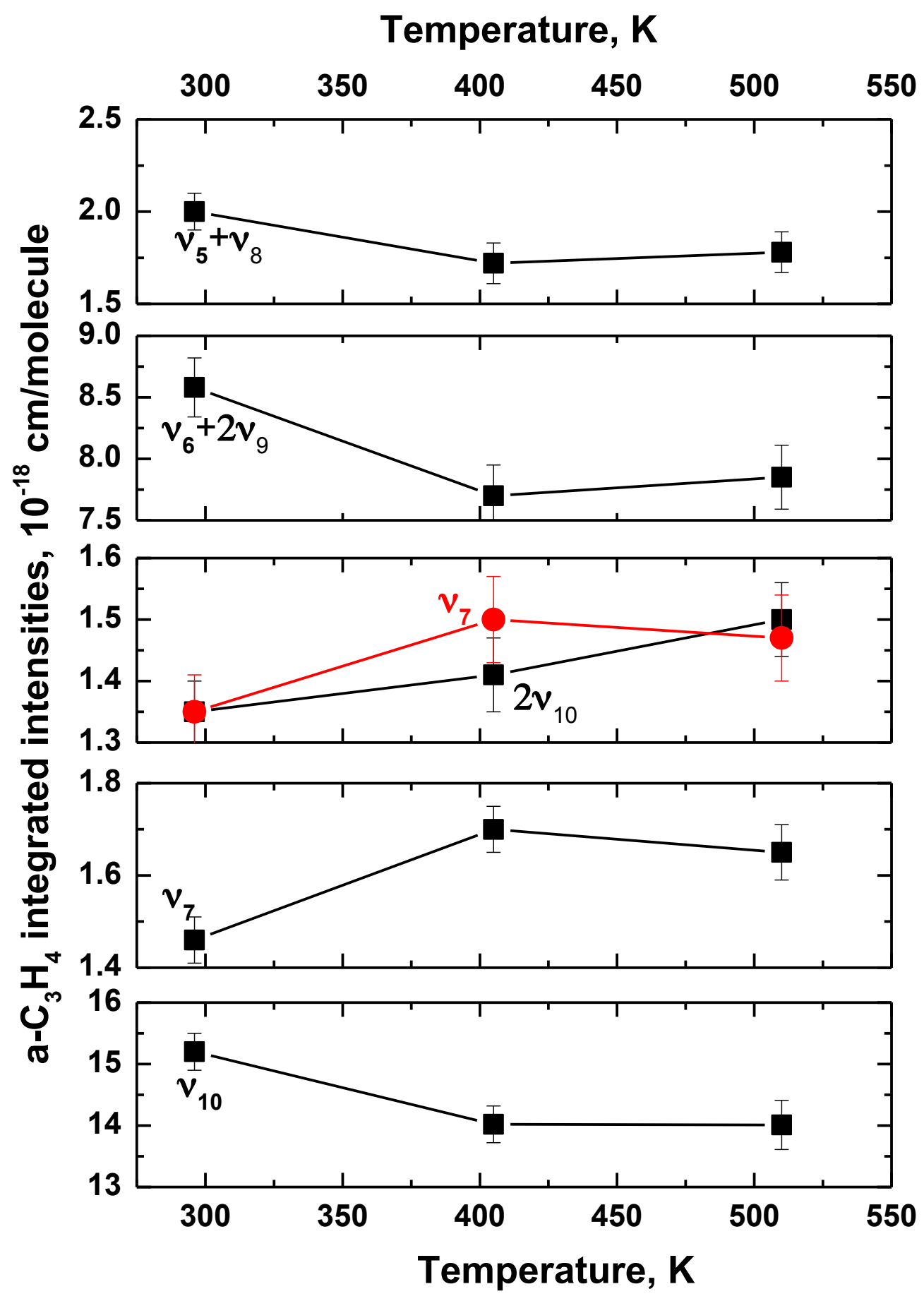


Fig. 5. Propyne absorption cross-section measured between 580 and $3400 \mathrm{~cm}^{-1}$ at $296 \mathrm{~K}$. Spectra are recorded with $4 \%$ propyne/ $\mathrm{N}_{2}$ mixture and a total pressure between 150 and 400 Torr (see text). The main features are identified and summarized in Table 3. Spectra in the $700-1300 \mathrm{~cm}^{-}$ ${ }^{1}$ are recorded at a resolution of $0.08 \mathrm{~cm}^{-1}$ and spectra in the $1300-3400 \mathrm{~cm}^{-1}$ are recorded at $0.25 \mathrm{~cm}^{-1}$ resolution
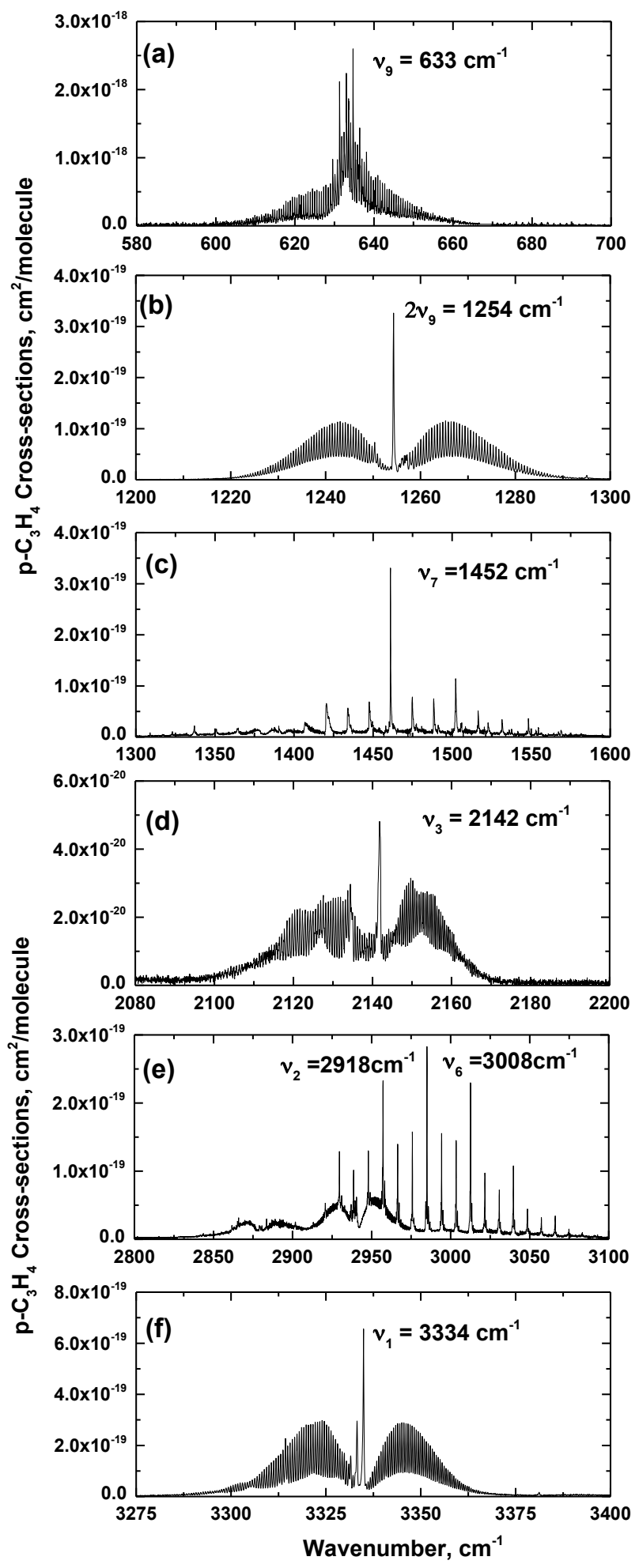
Fig. 6. Integrated absorbance (base-e) of propyne as a function of the product of its partial pressure and optical path length for various wavenumber regions. Spectra are recorded with a mixture of $4 \% \mathrm{p}-\mathrm{C}_{3} \mathrm{H}_{4} / \mathrm{N}_{2}$ for a maximum total pressure of 150 Torr in the case of $580-700 \mathrm{~cm}^{-}$ ${ }^{1}$ region and $1 \mathrm{~atm}$ for all other spectral regions.

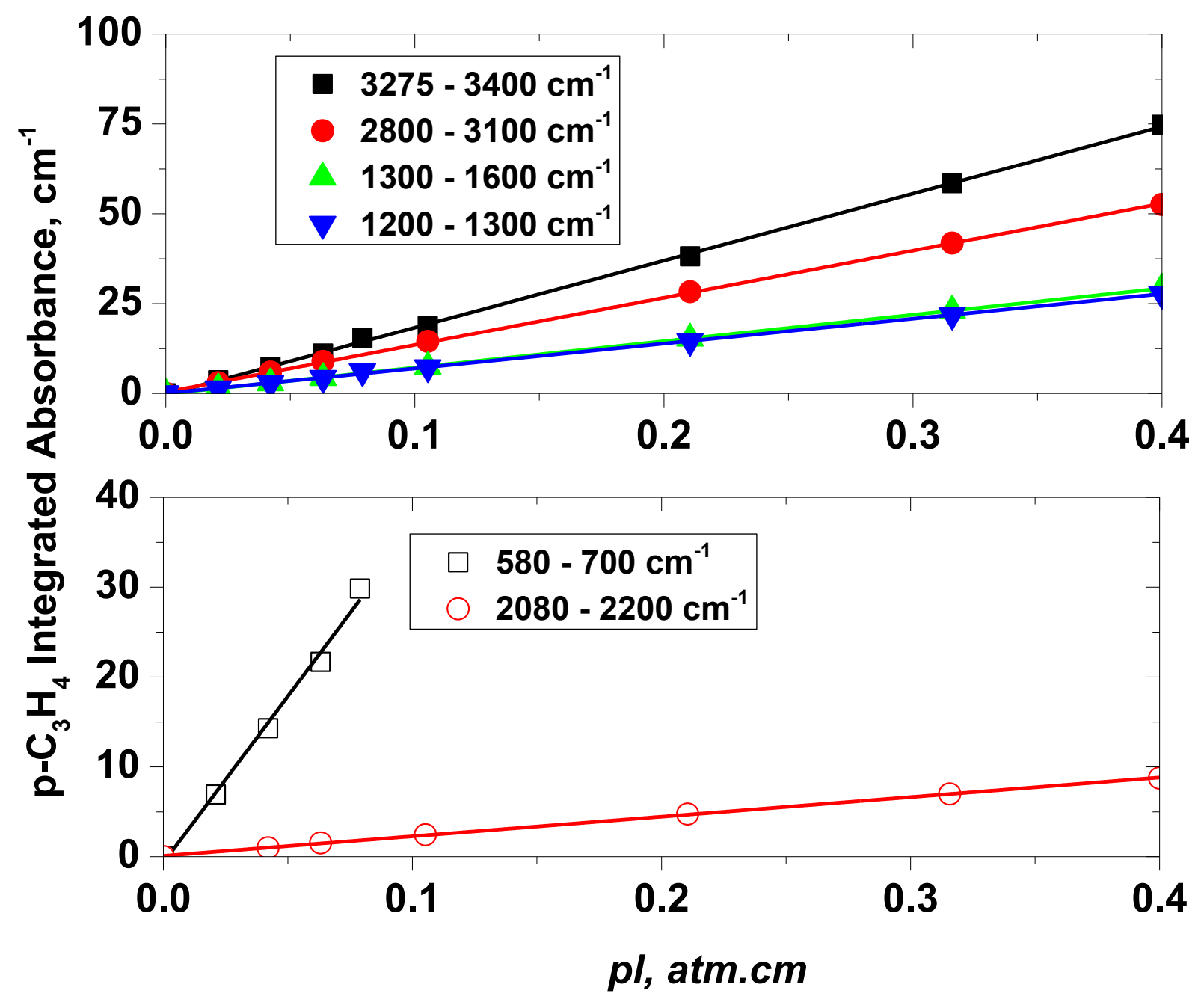


Fig. 7. IR cross-section measurements of $\mathrm{p}-\mathrm{C}_{3} \mathrm{H}_{4}$ at 296, 361, 405 and $493 \mathrm{~K}$. Spectra are recorded with a pure sample at low pressures: ( 2 Torr in $580-700 \mathrm{~cm}^{-1}$ range and 10 Torr for all other spectral domains). The resolution is $0.08 \mathrm{~cm}^{-1}$ in the $700-1300 \mathrm{~cm}^{-1}$ range and $0.25 \mathrm{~cm}^{-1}$ between 1300 and $3400 \mathrm{~cm}^{-1}$

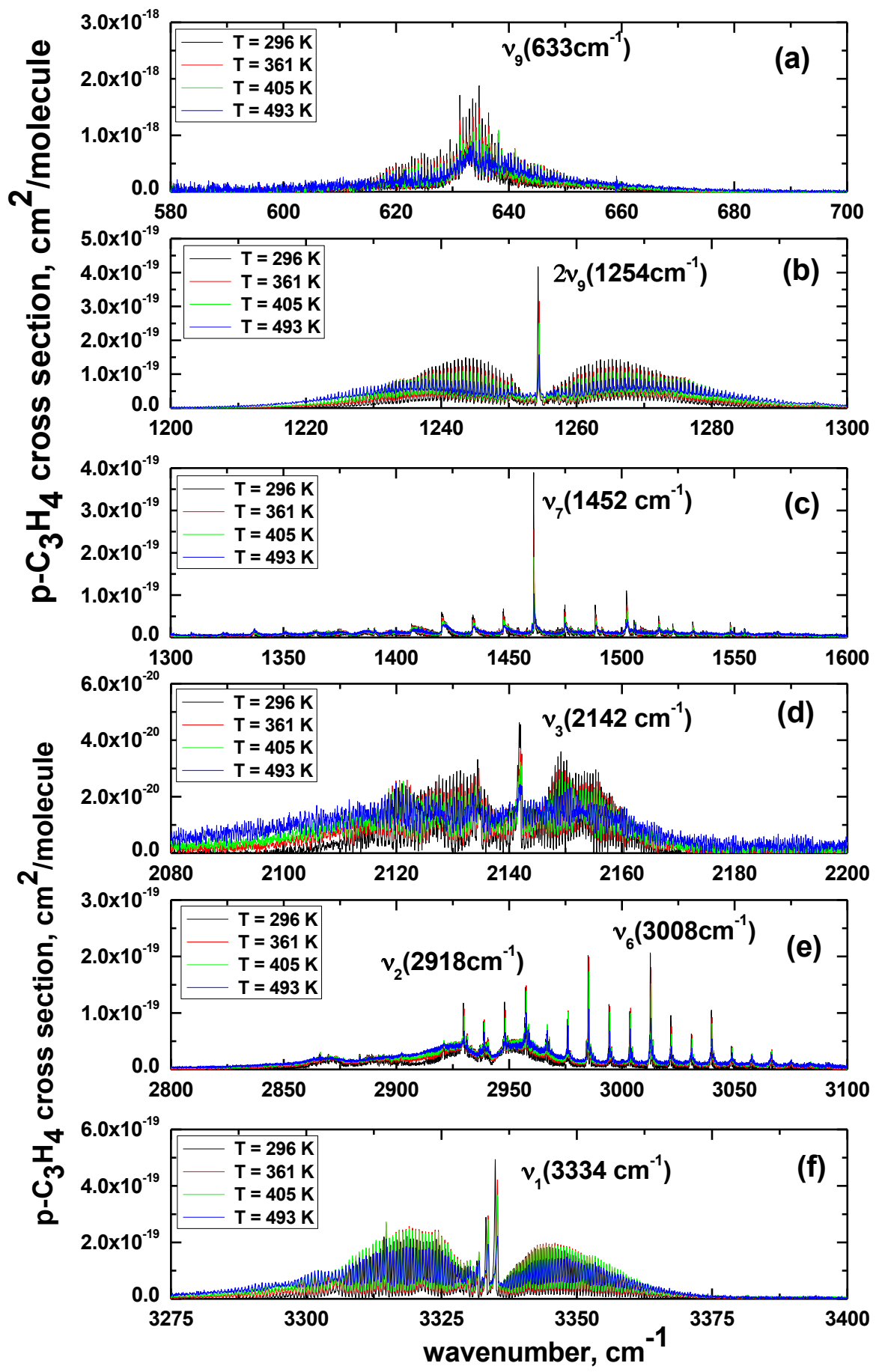


Fig. 8. Integrated band intensities as a function of temperature for various bands of $\mathrm{p}-\mathrm{C}_{3} \mathrm{H}_{4}$.

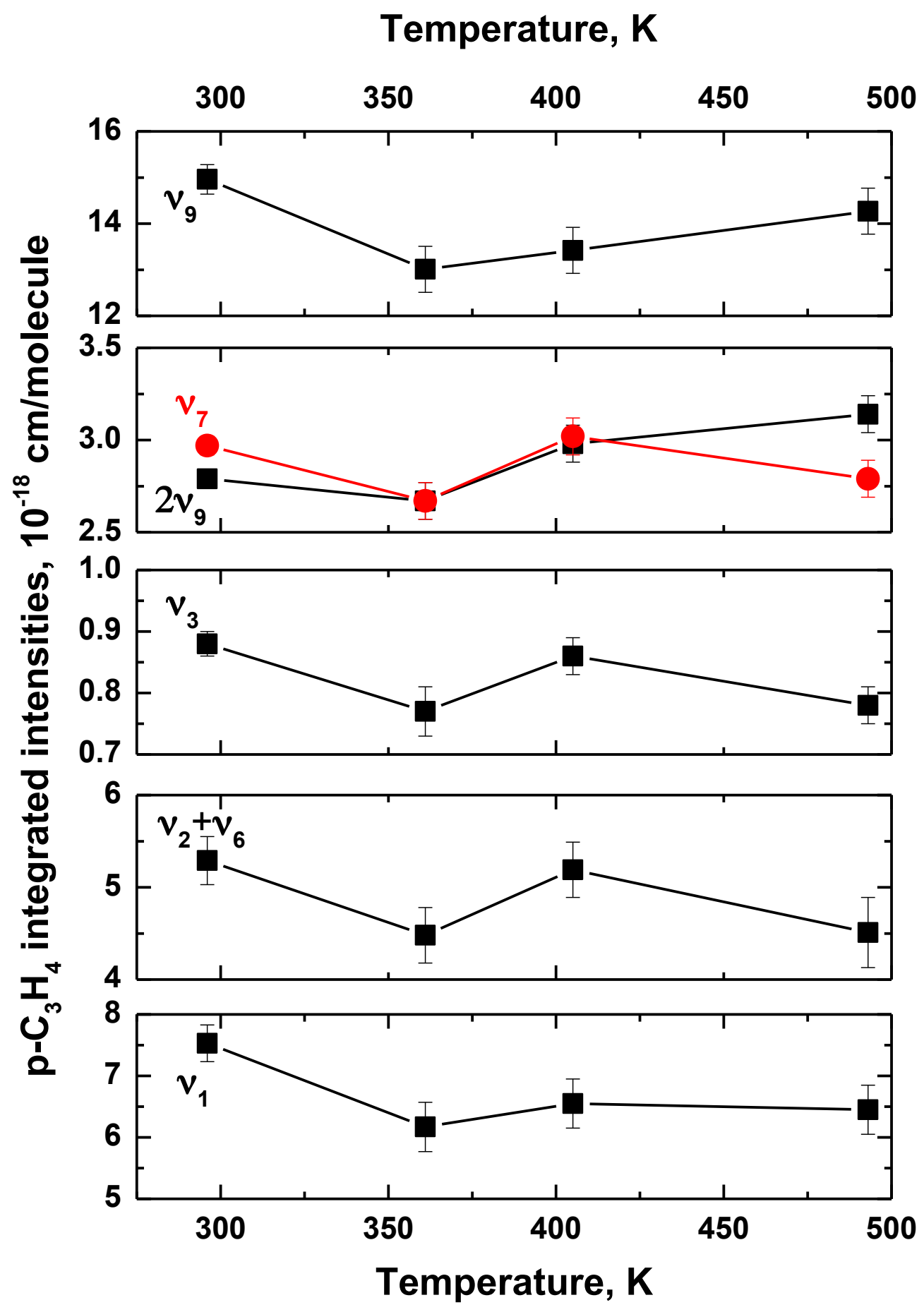

